\title{
La importancia de la evaluación como paso previo a la implementación de una moneda complementaria. Un estudio de caso rural en Ecuador, la parroquia Sinincay
}

\author{
Bolívar Ismael Amoroso Peralta \\ Diego Fernando Roldán Monsalve
}

RESUMEN: Numerosas son las experiencias de sistemas monetarios complementarios al oficial en diferentes países, tanto desarrollados como en desarrollo. También son numerosos sus éxitos y fracasos, así como los escenarios en que cada uno de esos proyectos se ejecutó. Existe apoyo estatal en algunos casos y prohibición absoluta en otros. No se trata únicamente de una adecuada planificación interna del proyecto, es también importante determinar si se cuenta con un escenario adecuado para su funcionamiento, considerando sus propósitos y las condiciones socioeconómicas de la población intervenida. En el presente estudio analizamos las posibles causas del fracaso de una experiencia en un pueblo rural andino en Ecuador. Considerando que los proyectos de monedas complementarias no comparten todas sus objetivos, ni tampoco presentan escenarios socioeconómicos similares, no se espera que todas las poblaciones intervenidas cumplan las mismas condiciones de partida, sin embargo, es necesaria la evaluación de un grupo de requisitos para cada caso. Mediante un análisis cualitativo, de acuerdo a la literatura revisada, identificamos un grupo de condiciones que justifiquen la implantación de un sistema complementario y, basados en los testimonios de promotores y participantes, analizamos en qué medida estas se cumplieron antes de implantar el proyecto. Para el caso de estudio, se concluyó que no existieron las condiciones adecuadas para que esta moneda complementaria cumpla con los objetivos económicos y sociales propuestos.

PALABRAS CLAVE: Sistemas monetarios complementarios, UDIS, condiciones socioeconómicas favorables, desarrollo local.

CLAVES ECONLIT: O23, E51, E52, E58.

Cómo citar este artículo / How to cite this article: AMOROSO, B.I. \& ROLDÁN, D.F. (2019): "La importancia de la evaluación como paso previo a la implementación de una moneda complementaria. Un estudio de caso rural en Ecuador, la parroquia Sinincay", CIRIEC-España, Revista de Economía Pública, Social y Cooperativa, 97, 279-312. DOI: 10.7203/CIRIEC-E.97.13412.

Correspondencia: Bolívar Ismael Amoroso Peralta, ismael.amoroso@yahoo.com, y Diego Fernando Roldán Monsalve, roldandie@yahoo.com (contacto), Universidad de Cuenca - Ecuador. 


\section{EXPANDED ABSTRACT}

\section{The importance of evaluation as a preliminary step to the implementation of a complementary currency. A rural case study in Ecuador, the Sinincay parish}

\section{Objectives}

At present, both the scarcity of money and its inadequate distribution have negative consequences for its population, which, together with other causes, has promoted initiatives of complementary monetary systems (CMS) to the official ones. These alternatives seek to palliate the adverse effects of an inefficient orthodox monetary system, although for some authors, this is equivalent to an inorganic emission of money and consequently generates inflation.

For Meyer and Hudon (2018), the CMSs are no longer a small-scale phenomenon, even less so if we consider that there are more than 3000 Community currency projects, and some with a long history such as the WIR in Switzerland or the Sardex in Sardinia.

From the perspective of Schuldt (1997), Santana (2011), and Lietaer and Belgin (2011), a SMC aims to diminish various effects caused by an economic crisis, reflected in the scarcity of currency, income scarcity, high unemployment rates, inability to access the financial system, high interest rates, and therefore, in a contraction of supply and an increase in monetary demand.

However, these scenarios alone would not guarantee the success of the CMSs. In fact, Schuldt (1997) mentions that it will also depend on a series of prerequisites or preconditions to be met by the locality to be implemented by the project, covering economic, monetary, psycho-sociological, educational, institutional, cultural, political and productive specialization aspects.

With this background, in Ecuador, in the parish of Sinincay, in 2011, a CMS called Solidarity Exchange Unit (UDIS) was implanted. This project was operated by a savings and loans cooperative with the support of national entities and a foreign entity, the STRO Foundation of the Netherlands, an institution with experience in similar projects with partially positive results.

In our case study, despite the efforts of the sponsoring institutions, the UDIS project had limited interest, few participants, and lasted barely a year, despite open government support. 


\section{LA IMPORTANCIA DE LA EVALUACION COMO PASO PREVIO A LA IMPLEMENTACION DE UNA MONEDA COMPLEMENTARIA. UN ESTUDIO DE CASO RURAL EN ECUADOR, LA PARROQUIA SININCAY}

In this study, from the theoretical perspectives of the CMSs, we asked whether Sinincay had the necessary and sufficient conditions for the functioning and success of the UDIS, in order for it to meet a socio-economic objective. Our hypothesis is that the failure of the project is due to the fact that the population of Sinincay did not meet the necessary and sufficient conditions for the operation of a monetary scheme of this type.

\section{Methodology}

To answer this question, we resorted to qualitative research. We proposed a two-stage evaluation method: First, it is necessary to review in the literature the socio-economic conditions conducive to the proper functioning of a CMS. Secondly, it is necessary to obtain information to verify the level of compliance with these requirements. In this second step, considering the limited socioeconomic information from our case study and institutional data from the project, we proceeded with interviews with former officials of the sponsoring institutions, ex-participants in the project and some non-involved citizens in order to, based on their testimonies, evaluate compliance with the required conditions. It should be noted that the cooperative that was in charge of the project no longer exists.

We have not found other studies that seek to answer a question similar to that of this research and that serve us as a starting point and discussion. First of all, the appropriate socio-economic conditions for the functioning of the UDIS were determined, based mainly on Schuldt's studies (1997) and on the experiences of other CMSs in different countries. The empirical evidence to contrast the fulfilment of the socioeconomic conditions necessary for the proper functioning of the UDIS was obtained basically through in-depth interviews with the social actors related to that project.

Three types of structured interviews were designed: the first one applied to 4 officials of the promoting institutions; secondly, an interview was applied to 11 participants (users) of the system. Thirdly, a control group made up of 29 microenterprise informants who did not participate in the project. The questions were asked in order to establish the level of compliance with each of the conditions considered.

\section{Results}

According to the information provided by the interviewees, the members of the network could freely purchase UDIS in the Cooperative, paying 0.90 USD for each UDIS of nominal value 1 USD and there was no limit amount for the purchase of this currency. According to the interviewees, there was no minimum or maximum period to reconvert the UDIs into dollars for their nominal value (a 1 to 1 ratio).

According to subjective perceptions about the economic situation of the parish for a period of two years prior to the implementation of UDIS, none of the six required conditions were met. 
According to the subjective perceptions of the minimum conditions established by Schuldt, five are not fulfilled, two are partially fulfilled and only one is fulfilled.

Concerning the dynamics of the functioning of the heterodox monetary system, two conditions are not fulfilled, three are partially met and none are fully met.

With regard to the perception of the causes that led to the completion of the project, and based on the information gathered, the causes have been categorized by internal and external factors that affected the proper functioning of the UDIS scheme.

Among the internal factors that the actors considered are: the scarce circulation of the UDIS; the little acceptance of them; little productive diversity; little information and training on the subject; economic individualism.

The following external factors were considered: the media boom that at the time distorted the conception and purpose of the project, even suggesting that it was illegal and that it was intended to displace the dollar as the official currency; and the legal prohibition that prevented popular and solidarity financial entities from managing all kinds of alternative means of payment.

\section{Conclusions}

Authors such as Schuldt (1997) and Gesell (1936), who helped us to identify requirements for the success of the CMSs, do not specify whether all the conditions they mention are indispensable, but it can be assumed that this is not necessarily the case, since there are successful cases with or without oxidation in the design, with or without the presence of crisis in the socioeconomic characteristics. However, it is to be expected that a CMS is justified as long as it is constituted as a resource to cover some type of deficiency of the official monetary system and that the community involved trusts the resource.

Based on the evidence, our conclusion is that the UDIS did not have an adequate prior analysis to identify the socioeconomic conditions in which it would play an important role and, above all, had it been done, it would have been determined that the conditions prior to the project were not conducive to implementing a CMS. According to the testimonies, Sinincay was too integrated into the economic dynamics of the city of Cuenca, rather than among the people of the parish. On the other hand, the dollars that circulated among its inhabitants, increased by the significant remittances of its migrants, do not show weaknesses in the official currency, reinforced by a provision of credits considered as affordable. 


\section{LA IMPORTANCIA DE LA EVALUACION COMO PASO PREVIO A LA IMPLEMENTACION DE UNA MONEDA COMPLEMENTARIA. UN ESTUDIO DE CASO RURAL EN ECUADOR, LA PARROQUIA SININCAY}

\section{Contribution}

The importance of this research lies in the methodological proposal for assessing the appropriate conditions for the functioning of a CMS. The results of this research warn the control institutions that a project of this nature must have such an evaluation before its operation in order to avoid wasting resources.

KEYWORDS: Complementary monetary systems, UDIS, favourable socio-economic conditions, local development.

\section{Introducción}

\subsection{Algunos éxitos y fracasos de sistemas monetarios complementarios}

El dinero es un medio de intercambio de bienes y servicios, una medida de valor y permite el atesoramiento de este (Orzi, 2012; Rothbard, 1979; Keynes, 1943; Gesell, 1936). En una economía moderna, la escasez de este recurso, así como su inadecuada distribución, traen consecuencias negativas para su población, lo que, junto con otras causas, ha promovido iniciativas de monedas alternativas o complementarias a las oficiales, buscando paliar los efectos adversos de un sistema ortodoxo ineficiente.

Sin embargo, en la actualidad, la política monetaria a lo largo del planeta no parece compatibilizar con la emisión de dinero por parte de entidades financieras ajenas al Estado. Si bien en el siglo XIX fue muy difundida la política que permitía a los bancos privados emitir su propio dinero (free banking), como consecuencia de las crisis de inicios del siglo XX, esta fue sustituida por un control monopólico de los bancos centrales justificándose en argumentos como la emisión inorgánica del dinero y su consecuente inflación. Para Keynes, estos bancos centrales son parte de un remedio ajeno al mercado para una enfermedad del mercado (Garrison, 1996).

Desde esta perspectiva, las monedas complementarias pueden ser cuestionadas por equipararse a un caso más de free banking. Para Gesell (1936), este mecanismo de libre moneda es una opción, pero requiere eliminarse su función de atesoramiento manteniendo únicamente la de medio de pago (Louge, 2017). En todo caso, Para Meyer y Hudon (2018) los proyectos de monedas complementarias ya no constituyen un fenómeno de pequeña escala, menos aún si consideramos que, según Seyfang y Longhurst (2013), existen más de 3000 proyectos de monedas comunitarias, y algunas con larga historia. En Suiza, la moneda complementaria WIR se encuentra vigente desde 1934, cuenta con 
más de 50.000 miembros que representan el $17 \%$ del total de negocios de ese país y permite el intercambio de casi el $2 \%$ del PIB suizo (IMS, 2015).

El Sardex fue creado en Cerdeña en 2006 con el objetivo de mejorar el comercio local afectado por problemas económicos locales, nacionales e internacionales. En la actualidad más de 4.000 empresas forman parte del proyecto.

Este tipo de prácticas, bajo el marco de un sistema monetario complementario (SMC), han sido frecuentes a lo largo del siglo XX hasta la actualidad, con diferentes diseños de funcionamiento (Meyer \& Hudon, 2018) a través de proyectos como: Wära en Alemania, Wörgl en Austria, Paper Scrip en Estados Unidos, LETS en Canadá, Bonos Salteños en Argentina, Banco Palmas en Brasil, Tlaloc en México, Ithaca Hours en Estados Unidos, UDIS en Centroamérica y muchos casos más, de las cuales varias se encuentras vigentes (Véase Tabla 1).

\section{Tabla 1. Experiencias de sistemas monetarios alternativos (SMC)}

\begin{tabular}{|c|c|c|c|c|c|}
\hline Experiencias & País (es) & $\begin{array}{c}\text { Fecha } \\
\text { creación }\end{array}$ & $\begin{array}{l}\text { Fecha } \\
\text { cierre }\end{array}$ & $\begin{array}{l}\text { Motivo } \\
\text { del cierre }\end{array}$ & Observaciones \\
\hline Wära & Alemania & 1929 & 1931 & $\begin{array}{l}\text { Disposición del Banco } \\
\text { Central y el Ministerio de } \\
\text { Finanzas de Alemania }\end{array}$ & \\
\hline Wörgl & Austria & 1932 & 1933 & $\begin{array}{l}\text { Disposición de la Banca } \\
\text { Nacional Austriaca y la Corte } \\
\text { Suprema de Viena }\end{array}$ & \\
\hline Wir & Suiza & 1934 & En uso & & \\
\hline $\begin{array}{l}\text { Paper } \\
\text { Scrip }\end{array}$ & EE.UU. & 1932 & & & $\begin{array}{l}\text { Algunas duraron hasta finales de la } \\
\text { década de los } 30 \text { 's, otras experiencias } \\
\text { se mantienen hasta la actualidad. }\end{array}$ \\
\hline LETS & Canadá & 1983 & En uso & & \\
\hline $\begin{array}{l}\text { Bonos } \\
\text { Salteños }\end{array}$ & Argentina & 1984 & $\begin{array}{c}\text { Finales } \\
\text { de los } 90 \text { 's }\end{array}$ & Desuso de la moneda & \\
\hline Ithaca Hours & EE.UU. & 1991 & En uso & & \\
\hline $\begin{array}{l}\text { Banco } \\
\text { Palmas }\end{array}$ & Brasil & 1998 & En uso & & $\begin{array}{l}\text { Según Scalfoni y Carvalho (2017) se ha } \\
\text { evidenciado el desuso de la moneda }\end{array}$ \\
\hline Tlaloc & México & 1996 & En uso & & $\begin{array}{l}\text { Según Santana (2011) se ha evidenciado } \\
\text { un desuso de la moneda. }\end{array}$ \\
\hline UDIS & $\begin{array}{l}\text { Honduras, } \\
\text { Costa Rica, } \\
\text { El Salvador }\end{array}$ & 2003 & Uso parcial & & $\begin{array}{l}\text { Según Sánchez (2019), en } \\
\text { Honduras dejó de usarse en } 2007 .\end{array}$ \\
\hline
\end{tabular}

FUENTE: Elaboración propia.

CIRIEC-España, Revista de Economía Pública, Social y Cooperativa 


\section{LA IMPORTANCIA DE LA EVALUACION COMO PASO PREVIO A LA IMPLEMENTACION DE UNA MONEDA COMPLEMENTARIA. UN ESTUDIO DE CASO RURAL EN ECUADOR, LA PARROQUIA SININCAY}

\subsection{Propósitos de los sistema monetarios complementarios}

Cuando un sistema monetario oficial de un país no puede satisfacer los requerimientos de una comunidad, se puede optar por el trueque o por la implantación de un SMC. En el caso del trueque, tal como mencionan Rothbard (1979), Zelmanovitz (2011) y Wild (2011), es un mecanismo que estuvo presente mucho antes de la aparición del dinero. A raíz de la evolución en la especialización y división del trabajo, así como también del crecimiento de las comunidades, un tipo de comercio basado en el trueque fue menos eficiente por diferentes razones como la expansión de las fronteras comerciales, 0 la necesidad de cambios fraccionarios entre varios productores. Estas dificultades también reaparecen en las nuevas iniciativas de trueque, obstaculizando su aplicación en mercados actuales.

En cuanto a los SMCs, aparecen de forma notoria como propuestas frente a los inconvenientes resultantes de la Gran Depresión en algunas comunidades europeas y norteamericanas, y aún más luego de la Segunda Guerra Mundial (Zagata, 2004). Algunos de estos esquemas tienen influencia en mayor o menor medida por las propuestas teóricas de Silvio Gesell en su publicación de 1916 "El Orden Económico Natural" (idioma alemán), las cuales fueron valoradas positivamente por teóricos económicos como Fisher y Keynes.

Otro elemento importante para entender el rol de un SMC es el problema que surge en la conformación del dinero bancario. Esta creación monetaria por parte de la banca es considerada por autores como Hirota (2012), Lietaer y Belgin (2011) y Greco (2003) como uno de los fallos estructurales del sistema monetario actual, el cual obliga a que cada vez se tenga que crear más dinero (bancario) para que los deudores tengan lo suficiente como para devolver el capital más el interés generado.

Al respecto, Hirota (2012) sostiene que, asumir como crédito bancario la creación de dinero implica que para que el dinero permanezca en circulación requiere la permanente existencia de deudores. Bajo esta perspectiva, el mismo autor indica que no hay dinero si no hay deuda "no debt no money".

La espiral de demanda monetaria antes descrita sugiere que el sistema crediticio bancario propicia una escasez monetaria, lo que es considerado uno de los fallos estructurales del sistema monetario actual, como lo resaltan Corrons (2015), Hirota (2012), Douthwaite (2000), Lietaer (2005), Schuldt (1997), entre otros.

Por otra parte, el sistema monetario convencional permite el atesoramiento del dinero por parte de los agentes económicos, ya que no adolece de desgaste y deterioro como otras mercancías, lo que, según Boisguilbert, citado por Schuldt (1997), hace del dinero una mercancía "mejor" o superior a todas las demás.

Desde otra perspectiva, el atesoramiento del dinero tiene una influencia muy fuerte sobre la cantidad monetaria en una economía, la cual puede ser mayormente evidenciable en situaciones críticas. De hecho, cuando se genera una crisis económica y cuando el crédito se contrae, la oferta de la 
moneda también lo hace, lo cual dificulta un comercio de manera normal. Mientras hay menos moneda, las personas, los gobiernos y las instituciones financieras retienen el efectivo que poseen y dejan de prestar a otros, dando como resultado una oferta limitada de dinero afectando la dinámica de las transacciones.

Ante estos inconvenientes, que incluso pueden intensificarse frente a crisis, recesiones o depresiones económicas, es posible optar por un SMC que funcione de manera paralela al sistema oficial, permitiendo contrarrestar esta escasez de oferta monetaria1. Una moneda adicional operando paralelamente a la oficial, incrementa la oferta de dinero.

Desde la perspectiva de Schuldt2 (1997), Santana (2011), y Lietaer y Belgin (2011), un SMC tiene como objetivo disminuir diversos efectos causados por una crisis de tipo económica, reflejados en la escasez de circulante, escasez de ingresos, elevadas tasas de desempleo, incapacidad para acceder al sistema financiero, elevadas tasas de interés por acciones crediticias, y por lo tanto, en una contracción de oferta y un incremento de la demanda monetaria.

No obstante, estos escenarios no garantizarían por sí solos el éxito de los SMCs. De hecho, Schuldt (1997) menciona que dependerá también de una serie de prerrequisitos o precondiciones que debe cumplir la localidad que vaya a implantar el proyecto y que abarcan aspectos económicos, monetarios, psicosociológicos, educativos, institucionales, culturales, políticos y de especialización productiva.

Por otra parte, no todo SMC tiene los mismos objetivos. Según DeMeulenaere (2007), su implementación puede tener uno o varios de los siguientes propósitos: facilitar la cooperación, desarrollo empresarial, activar el mercado local, reducir la necesidad de la moneda nacional, desarrollo comunitario, además de otros. Así por ejemplo, en algunas localidades con restricciones económicas este recurso busca contrarrestar lo que Polanyi (2001) describió como mercantilización del dinero, mientras que, en otros entornos como los especulativos posiblemente sea un medio de inversión financiera como son algunas criptomonedas. Esta situación puede condicionar a que los requisitos para el éxito de las monedas complementarias no necesariamente deben ser los mismos. En este estudio nos enfocamos en las primeras.

\subsection{Un caso fallido en Ecuador: las Unidades de Intercambio Solidario}

Desde abril de 2011, en Sinincay, parroquia rural ecuatoriana, se implantó un SMC denominada unidad de intercambio solidario (UDIS), la cual circulaba dentro de una red cerrada de intercambio de bienes y servicios (El Comercio, 2011). Este proyecto fue operado por la Cooperativa de Ahorro y

1.- Al respecto, Santana (2011) menciona que "en la actualidad, miles de monedas comunitarias en el mundo se están emitiendo para aliviar la escasez del dinero oficial" (p. 263).

2.- Quien recoge aportaciones importantes de Gesell, Boisguilbert, Proudhon, Fisher, entre otros. 


\section{LA IMPORTANCIA DE LA EVALUACION COMO PASO PREVIO A LA IMPLEMENTACION DE UNA MONEDA COMPLEMENTARIA. UN ESTUDIO DE CASO RURAL EN ECUADOR, LA PARROQUIA SININCAY}

Crédito Integral con apoyo de entidades nacionales como la Red Nacional de Finanzas Populares y Solidarias del Ecuador (RENAFIPSE), Fundación Pachamama; y una entidad extranjera, la Fundación STRO de Holanda, institución con experiencia en proyectos semejantes en Centro América (EI Salvador, Honduras y Costa Rica) con resultados parcialmente positivos.

Según Sánchez (2019), siendo la misma fundación la promotora, un sistema UDIS funcionó en Honduras durante cinco años (2003-2007) sin constituirse en un mecanismo esencial para la expansión de la comunidad campesina COMAL donde se implantó, aunque sostiene que colaboró en su cohesión social. Mientras que, en la comunidad El Silencio de Costa Rica, las UDIS, introducidas en 2007, son usadas al presente más que los colones, la moneda oficial. En la actualidad, la Fundación STRO ya no da más soporte a los proyectos UDIS 3 , en su lugar se han enfocado en el desarrollo de un software para sistemas de monedas locales denominado Cyclos.

En nuestro caso de estudio, las UDIS de la parroquia de Sinincay, a pesar del esfuerzo de las instituciones auspiciantes, el proyecto tuvo un limitado interés, apenas pocos participantes y duró escasamente un año, a pesar de un apoyo abierto por parte del gobierno del Presidente Correa.

En relación con el procedimiento, se iniciaba con la emisión de los billetes por la Fundación STRO. Luego, estos eran entregados a la Cooperativa de Ahorro y Crédito Integral para su administración y promoción en Sinincay. Los miembros participantes de la red podían adquirir sin ninguna restricción las UDIS con valor nominal de 1 USD pagando 90 ctvs. Se esperaba que este descuento del 10\% estimule el uso de UDIS para comprar bienes y servicios en la comunidad. Los negocios que reciben UDIS tendrían más demanda y podían con este dinero pagar a sus proveedores, dar vueltos a sus clientes, pagar a sus empleados o podían canjear en la misma cooperativa por dólares a su valor nominal, es decir 1 USD. El subsidio de las UDIS fue financiado por la Fundación Pachamama como gastos de promoción de este SMC.

Este proyecto fue cuestionado por políticos opositores al presidente Correa aduciendo que era un intento por parte del gobierno de iniciar un proceso de desdolarización de la economía. La Superintendencia de Bancos del Ecuador solicitó a la Dirección de Cooperativas del MIES que investigue sobre el sistema UDIS la que prefirió catalogarla como medio de pago y no como una moneda, evitando de esta manera su calidad de ilegal (EI Universo, 2011). Sin embargo, el debate sobre la legalidad de estas monedas alternativas se agudiza y finalmente, para el año 2012, se oficializa su prohibición dentro del sector financiero popular y solidario específicamente, aunque para entonces este proyecto UDIS ya estaba finalizando.

Para evitar su cierre, con el propósito de dar continuidad y legalidad al proyecto UDIS se conformó la Red de Intercambio Solidario Integral, entidad independiente del sistema financiero cooperativo, y que asumiría la gestión de este SMC, sin embargo, aunque esta estrategia solucionaba el problema 
de la ilegalidad, no pudo resolver los problemas aún más álgidos de su real funcionamiento que, según algunos entrevistados, existieron desde su inicio.

Con estos antecedentes y ante los riesgos de nuevas iniciativas SMC, consideramos necesario analizar las posibles causas de su fracaso. Nuestro argumento es que este recurso tendrá aceptación de la población si se constituye en un bien de uso, es decir, ser necesario para solventar problemas concretos en los que el sistema monetario oficial es ineficiente. De esta manera, debería localizarse ciertas características del contexto socioeconómico de la comunidad en las que las UDIS puedan colaborar.

Es este estudio, desde las perspectivas teóricas de los SMC, nos preguntamos si hubo en Sinincay las condiciones necesarias y suficientes para el funcionamiento y éxito de las UDIS, con el fin de que cumpla con un objetivo socioeconómico.

Nuestra hipótesis es que el fracaso del proyecto se debe a que la población de Sinincay no cumplía con condiciones necesarias y suficientes para el funcionamiento de un esquema monetario de este tipo.

Para responder esta pregunta recurrimos a la investigación cualitativa. Propusimos un método de evaluación que requiere dos etapas: En primer lugar, es necesario revisar los aportes de diferentes autores sobre condiciones socioeconómicas propicias para un funcionamiento adecuado de un SMC. En segundo lugar, es necesario obtener información para constatar el nivel de cumplimiento de dichos requisitos. En este segundo paso, considerando la limitada información socioeconómica de nuestro caso de estudio y de datos institucionales del proyecto, procedimos con entrevistas a exfuncionarios de las instituciones promotoras, a exparticipantes del proyecto y a algunos ciudadanos no involucrados para, con base en sus testimonios, evaluar el cumplimiento de las condiciones antes establecidas. Cabe indicar que la cooperativa que estuvo al frente del proyecto actualmente ya no existe.

En lo económico, cabe señalar que durante el período de funcionamiento de este sistema (20102012), a nivel macroeconómico el país se encontraba en una situación favorable en cuanto al crecimiento de la economía y la reducción de la pobreza, gracias, entre otros factores, al boom del precio del petróleo entre los años 2007 y 2014, tal como lo indica el Banco Mundial (2018). No obstante, como lo menciona Schuldt (1997), estos esquemas pueden ser aplicados en determinadas localidades marginadas o pobres de una nación, aunque el país en su conjunto pueda encontrarse macroeconómicamente en recuperación o incluso en pleno boom económico.

Este proyecto piloto fue realizado en la parroquia rural Sinincay. Según el censo de 2010, los habitantes de esta localidad eran 15.859 de los cuales, el 54\% eran mujeres, un porcentaje superior nacional de 50,44\%. Una población relativamente joven con una edad promedio de 28 años que coincide con el promedio nacional (28.36\%), autoidentificados en un $97 \%$ como mestizos, muy superior al porcentaje nacional (71,93\%). De las personas de 18 años o más, apenas el 13,85\% cuentan con afilia- 


\section{LA IMPORTANCIA DE LA EVALUACION COMO PASO PREVIO A LA IMPLEMENTACION DE UNA MONEDA COMPLEMENTARIA. UN ESTUDIO DE CASO RURAL EN ECUADOR, LA PARROQUIA SININCAY}

ción a la Seguridad Social (IESS,ISSFA, ISSPOL), siendo a nivel nacional 20,08\%, lo que sugiere que la mayor parte de la población trabajaba de manera autónoma o de manera informal ya que la tasa de desempleo de esta parroquia fue apenas el 2,07\%, menor al porcentaje nacional que fue $5,02 \%$. (INEC, 2018)

Para determinar el cumplimiento de las condiciones y escenarios en los que fue aplicado el esquema UDIS, se utilizó principalmente técnicas de investigación cualitativa, tanto para la recolección como para el análisis de los datos, entrevistas estructuradas y análisis de contenido respectivamente. Así también, ciertos indicadores sobre todo sociales que se adhieren como parte de los escenarios y condiciones fueron calculados con base en el VII Censo de Población y VI de Vivienda realizado en el año 2010 en Ecuador.

Por otra parte, aunque existen estudios que hacen referencia a ciertas condiciones para que un SMC funcione, cabe indicar que no hemos encontrado en la literatura estudios de caso concretos en los que se evalúe el cumplimiento previo de dichas condiciones. Esto nos hubiera permitido contrastar con nuestro estudio. Por lo tanto, nos remitiremos únicamente a estudios de caso como Doria y Fantacci (2018), Bendell (2017) Hirota (2017), Fare y Ould Ahmed (2017), Corrons Giménez (2015), Brenes (2013), Cortés García (2008), Blanc (2002), entre otros, los que, aunque carezcan de esta evaluación previa de escenario, nos permiten obtener algunos elementos de interés para nuestro análisis.

\section{Metodología}

La presente investigación es básicamente cualitativa, concretamente un estudio de caso que busca determinar factores que incidieron en el fracaso de la implementación de un SMC denominada UDIS en la parroquia Sinincay.

No hemos encontrado otros estudios que busquen contestar una pregunta semejante a la de esta investigación y que nos sirvan como punto de partida y discusión. En tal virtud, proponemos un método que cubra dos etapas: en la primera buscamos establecer un grupo de condiciones socioeconómicas que pudieron haberse considerado como adecuadas para un arranque exitoso del proyecto, así como las características del diseño del sistema UDIS que converja con dichas condiciones. En segundo lugar, consideramos necesario obtener información que nos permita contrastar si dichas condiciones se cumplieron en un nivel adecuado para su correcto funcionamiento. Nivel adecuado que no implica el cumplimiento de todas las condiciones, pero si un nivel aceptable desde la subjetividad de esta propuesta. 


\subsection{Determinación de las condiciones socioeconómicas adecuadas}

Un SMC se basa en el principio de reciprocidad apoyando la cooperación entre los miembros de una comunidad (Zagata, 2004). Con esto se busca resolver dificultades de este colectivo que no se consigue con el sistema monetario oficial. Es por tanto pertinente suponer que las características socioeconómicas en las que un sistema de esta naturaleza puede ser útil están relacionadas con problemas que enfrenta esta comunidad.

\subsection{1. Ámbito de la localidad y aspectos sociodemográficos de su población}

De las experiencias de los sistemas Wära, Wörgl, WIR, Talent-Experiment, Palmas, Stamp Scrip, Patacones, Bonos Salteños, Ithaca Hours, Tlaloc, UDIS (Centroamérica) etc. podemos resumir las siguientes características:

- Crisis económica: la mayoría de estos experimentos surgieron para paliar crisis económicas como la de los años 30's, 70's, la post guerra. Incluso hay casos que fueron aplicados en épocas de auge económico, pero en ciertas localidades donde su realidad fue completamente distinta. (Steiner, 1961; Schuldt, 1997; Keynes, 1943; Gesell, 1936; Fisher, 1933).

- Elevado número de quiebras: sobre todo de empresas medianas y pequeñas (Fisher, 1933)

- Caída de la producción: provocando que los negocios disminuyan sus ingresos y muchas veces no tengan cómo pagar a sus empleados (Fisher, 1933).

- Elevados niveles de desempleo: si hay un elevado número de quiebras de las empresas locales, sumado a la caída de su producción, las empresas reducirán sus ingresos, propiciando el despido a sus trabajadores (Keynes, 1943; Fisher, 1933; Gesell, 1936).

- Reducción de la masa monetaria: por atesoramiento, porque se deja de prestar dinero o se presta a mayores tasas de interés, se agudiza la escasez monetaria (Proudhon, 1848, citado en Schuldt, 1997), lo que a su vez reduce la velocidad de circulación.

- Contracción del crédito: correlacionada con la reducción de la masa monetaria, que a su vez genera escasez del circulante. En ocasiones, a pesar de poseer la localidad recursos monetarios depositados en el sistema financiero local, este es transferido para colocarse en otras zonas más rentables.

- Altas tasas reales de interés vigentes: limita el acceso al crédito, y cuando no, se requiere mayor cantidad de dinero real para cubrir los intereses respectivos.

- Poco poder adquisitivo: poco dinero en manos de los consumidores, incluso una crisis de poder de compra como lo estipula Silvio Gesell.

Schuldt (1997: 261) plantea las siguientes condiciones mínimas para el funcionamiento de los SMCs:

- En lo económico: no es suficiente un SMC, si paralelamente en la localidad, no se promueve un número significativo de proyectos productivos.

- En la especialización productiva: buscar una localidad que se caracterice por una diversificación relativamente amplia de actividades. 


\section{LA IMPORTANCIA DE LA EVALUACION COMO PASO PREVIO A LA IMPLEMENTACION DE UNA MONEDA COMPLEMENTARIA. UN ESTUDIO DE CASO RURAL EN ECUADOR, LA PARROQUIA SININCAY}

- En lo monetario: el sistema de intercambio debería funcionar paralelo al convencional (muy difícilmente alternativo) y que, como el dinero, no solo lo facilite, sino que también permita recoger información adecuada y eficaz por parte de compradores y vendedores. Habrá ciertos bienes y/o servicios que se demanden dentro de la localidad pero que no necesariamente se puedan producir dentro de la misma, razón por la cual necesitarán de dinero convencional para su adquisición.

- En lo institucional: debe existir un grupo o conjunto de entidades y personas capaces de liderar el proceso, introduciendo, divulgando, organizando, controlando, garantizando y asegurando la continuidad del sistema.

- En lo psicosociológico: la comunidad debe estar convencida de que el proyecto tendrá éxito, mantener una motivación adecuada, haber sido consultada respecto a sus características y haber participado en el diseño. También debe existir un cierto nivel de solidaridad y comunidad de intereses, etc., puesto que resulta menos probable que el sistema germine en localidades caracterizadas por rencillas internas, conflictos políticos, intereses exageradamente diversos, etc.

- En lo educativo: Para que los participantes se informen adecuadamente de propósito y funcionamiento del SMC conviene que los participantes no sean analfabetos. Los que habrían de liderar el proceso tendrían que haber culminado la secundaria como mínimo (en caso de los pueblos); y cuanto mayor sea el ámbito de acción del programa, mayores serán también las exigencias en términos de capacitación y hasta educación postsecundaria.

- En lo cultural: lo ideal es que exista un conjunto de normas, expectativas y valores relativamente comunes entre los miembros o participantes del sistema.

- En lo político: generalmente los participantes en estos sistemas son conscientes de las dificultades de la comunidad y cuestionan el esquema monetario oficial, los ingresos "no trabajados" (tasas de interés propias), e incluso, en algunos casos, también al sistema económico y social establecido. Estos posicionamientos permiten aglutinar intereses concordantes para así implantar un SMC más fluido y con mayor convencimiento por parte de los participantes.

\subsubsection{En el ámbito del proceso de funcionamiento del sistema}

- Estudio previo: según Schuldt (1997):

La aplicación de un sistema monetario heterodoxo alternativo, exige un estudio detallado de las condiciones locales, de las limitaciones económicas y culturales existentes, de las posibilidades y recursos disponibles, de las bases sociales de apoyo, de las instituciones y gremios existentes, considerando las tendencias de la coyuntura y de la idiosincrasia de la población, para adaptarlas consensualmente a las condiciones específicas de la realidad en que habrá de iniciarse y funcionar el sistema que se elija (p. 218)

- Surgir desde los actores sociales: Propuestas que surgen desde los actores sociales por iniciativa propia.

- Validez circunscrita en el tiempo y espacio: considerando la visión Geselliana y con valida- 
ciones de Fisher, el dinero heterodoxo, debe tener una validez circunscrita en el tiempo y el espacio. Tiempo según lo planificado y una zona determinada de circulación.

- Oxidación o depreciación programada: debe aplicarse mecanismos de depreciación u oxidación que aliente su circulación y evite el atesoramiento (Gesell 1916, Fisher 1933). Debe haber un envejecimiento programado (oxidación) del dinero no convencional. Por ejemplo, con el uso de estampillas que deben ser adheridas cada cierto tiempo dándole validez al dinero no oficial (Impuesto al atesoramiento). La suma acumulada de los pagos que se hacen por concepto de depreciación no debe exceder 0 ser igual al valor nominal del billete o cupón (Gesell, 1936). Adicionalmente, este costo de oxidación debe financiar el proyecto. Esta característica puede ser útil cuando el propósito es obligar a dinamizar el mercado local y evitar el atesoramiento, sin embargo, este dinamismo y no atesoramiento pueden surgir naturalmente como consecuencia de un mayor circulante en la comunidad. De hecho, SOL-Violette en Francia y Chiemgauer en Alemania usan la oxidación, mientras que Bristol Pound en Reino Unido y Eusko en Francia no la usan, y los cuatro sistemas son vigentes.

- Canje: el canje del dinero heterodoxo por el dinero oficial en cualquier momento antes de su vencimiento suele aplicar un impuesto adicional, similar a la cuota de oxidación.

- Tiempo de uso: se utilizan temporalmente como sustitutos de una parte del dinero que no circula, su duración es corta, generalmente de un año.

La Tabla 2 describe la manera en la que se obtuvo información sobre los escenarios y las condiciones en mención. 


\section{Tabla 2. Escenarios y/o condiciones}

\begin{tabular}{|c|c|}
\hline $\begin{array}{l}\text { Escenarios y/o } \\
\text { condiciones }\end{array}$ & $\begin{array}{l}\text { ¿Cómo se obtuvo y procesó la información? } \\
\text { Aplicado a grupo: Promotores(PR), participantes(PA), No participantes(NP) }\end{array}$ \\
\hline \multicolumn{2}{|c|}{$\begin{array}{l}\text { 1.- Condiciones económicas a nivel parroquial. Este grupo de condiciones se analizó considerando un período de dos año } \\
\text { previos a la aplicación de las UDIS en la parroquia Sinincay. }\end{array}$} \\
\hline Crisis económica & $\begin{array}{l}\text { Preguntas abiertas y uso de escalas de Likert respecto a la situación económica de la parroquia en } \\
\text { general y de los negocios locales. Interpretación de resultados mediante análisis de contenido (PR, PA) }\end{array}$ \\
\hline $\begin{array}{l}\text { Elevado número de quiebras } \\
\text { sobre todo de pequeños } \\
\text { emprendimientos }\end{array}$ & $\begin{array}{l}\text { Preguntas abiertas, sobre un cierre significativo de negocios y/o emprendimientos en la localidad. } \\
\text { Interpretación de resultados mediante análisis de contenido (PR, PA) }\end{array}$ \\
\hline Caída de la producción & $\begin{array}{l}\text { Preguntas abiertas sobre una caída en la producción y ventas de los negocios en Sinincay, así como } \\
\text { también en concreto de los negocios que participaron en este esquema. Interpretación de resultados } \\
\text { mediante análisis de contenido (PR, PA) }\end{array}$ \\
\hline $\begin{array}{l}\text { Elevados niveles de } \\
\text { desempleo }\end{array}$ & $\begin{array}{l}\text { Escenario analizado en dos momentos: el } 1^{\circ} \text { mediante el cálculo directo de la tasa de desempleo } \\
\text { para la parroquia a través del censo de población y vivienda efectuado en el año } 2010 \text {; el } 2^{\circ} \text {, mediante } \\
\text { una pregunta abierta a los participantes, la cual indaga sobre su situación laboral antes de ingresar al } \\
\text { proyecto de las UDIS. Interpretación de resultados mediante análisis de contenido. (PA) }\end{array}$ \\
\hline $\begin{array}{l}\text { Escasez de circulante } \\
\text { y/o poco poder adquisitivo }\end{array}$ & $\begin{array}{l}\text { Preguntas abiertas respecto a la impresión de escasez de circulante e incapacidad para comprar } \\
\text { bienes para el consumo y el desarrollo de las actividades productivas. Interpretación de resultados } \\
\text { mediante análisis de contenido (PR, PA) }\end{array}$ \\
\hline $\begin{array}{l}\text { Contracción del crédito y } \\
\text { altas tasas de interés } \\
\text { vigentes }\end{array}$ & $\begin{array}{l}\text { Preguntas abiertas sobre las facilidades o dificultades que los actores del esquema percibieron para } \\
\text { ingresar a los servicios de los sistemas financieros y sobre las tasas de interés activas que las } \\
\text { entidades financieras cobraban durante el período de referencia. Interpretación de resultados mediante } \\
\text { análisis de contenido (PR, PA) }\end{array}$ \\
\hline \multicolumn{2}{|c|}{ 2.- Condiciones mínimas para el funcionamiento de los SMC según Schuldt (1997) } \\
\hline En lo económico & $\begin{array}{l}\text { Preguntas abiertas sobre la existencia de proyectos productivos suficientes interesados en participar } \\
\text { en el proyecto UDIS. Interpretación de resultados mediante análisis de contenido (PR, PA) }\end{array}$ \\
\hline $\begin{array}{l}\text { En el campo de espe- } \\
\text { cialización productiva }\end{array}$ & $\begin{array}{l}\text { Preguntas abiertas sobre la diversidad de actividades que se ofertaban en la localidad. } \\
\text { Interpretación de resultados mediante análisis de contenido (PR, PA) }\end{array}$ \\
\hline En lo monetario & $\begin{array}{l}\text { Preguntas abiertas sobre el funcionamiento del esquema UDIS frente al oficial. Interpretación de } \\
\text { resultados mediante análisis de contenido (PR, PA) }\end{array}$ \\
\hline En lo institucional & Evaluación mediante escala de Likert de las capacidades de promotores para liderar proceso. (PR, PA) \\
\hline En lo psicosociológico & $\begin{array}{l}\text { Preguntas abiertas respecto al nivel de creencia de los actores en el sistema, mecanismos de } \\
\text { motivación utilizados por los promotores, participación de los usuarios en el diseño del proyecto. } \\
\text { Interpretación de resultados mediante análisis de contenido (PR, PA) }\end{array}$ \\
\hline En lo educativo & $\begin{array}{l}\text { Condición analizada en dos momentos: la primera, a nivel parroquial mediante el cálculo de las tasas } \\
\text { de alfabetismo y analfabetismo con base en los datos del censo de población y vivienda del año 2010, } \\
\text { con interpretación estadística; la segunda, obtenida directamente de los promotores y participantes a } \\
\text { través de la entrevista estructurada (PR, PA) }\end{array}$ \\
\hline En lo cultural & $\begin{array}{l}\text { Preguntas abiertas sobre los intereses en común de los participantes del sistema UDIS. } \\
\text { Interpretación de resultados mediante análisis de contenido. }\end{array}$ \\
\hline En lo político & $\begin{array}{l}\text { Preguntas abiertas sobre la situación económica y social del país en un período previo a las UDIS y } \\
\text { sobre el dólar como moneda de curso oficial. Interpretación de resultados mediante análisis de } \\
\text { contenido (PR, PA) }\end{array}$ \\
\hline
\end{tabular}

CIRIEC-España, Revista de Economía Pública, Social y Cooperativa 


\begin{tabular}{|l|l|}
\hline \multicolumn{3}{|l|}{ 3.- Dinámica de funcionamiento del sistema. Esta sección fue consultada únicamente a los promotores del esquema UDIS. } \\
\hline Estudio previo & $\begin{array}{l}\text { Preguntas abiertas sobre la existencia de un estudio de factibilidad previo a la aplicación del proyecto } \\
\text { y los actores que participaron en el mismo. Interpretación de resultados mediante análisis de } \\
\text { contenido (PR) }\end{array}$ \\
\hline $\begin{array}{l}\text { Validez circunscrita en } \\
\text { el tiempo y espacio }\end{array}$ & $\begin{array}{l}\text { Preguntas abiertas referente al tiempo por el cual podía ser utilizado un billete UDIS, así como } \\
\text { sobre su uso fuera de la localidad. Interpretación de resultados mediante análisis de contenido (PR) }\end{array}$ \\
\hline $\begin{array}{l}\text { Oxidación o depreciación } \\
\text { programada }\end{array}$ & $\begin{array}{l}\text { Preguntas abiertas respecto a la existencia de mecanismos de depreciación u oxidación para las UDIS. } \\
\text { Interpretación de resultados mediante análisis de contenido (PR) }\end{array}$ \\
\hline Emisión y Canje & $\begin{array}{l}\text { Preguntas abiertas sobre el proceso de emisión y canje de las monedas alternativas por dinero } \\
\text { oficial, y de los impuestos o multas aplicados en el caso de canjes en cualquier momento. } \\
\text { Interpretación de resultados mediante análisis de contenido (PR) }\end{array}$ \\
\hline Tiempo de funcionamiento & $\begin{array}{l}\text { Preguntas abiertas respecto al tiempo previsto por los promotores del esquema para el funcionamiento } \\
\text { del mismo. Interpretación de resultados mediante análisis de contenido (PR) }\end{array}$ \\
\hline $\begin{array}{l}\text { 4.- Causas del desuso del esquema UDIS } \\
\text { UDIS }\end{array}$ & $\begin{array}{l}\text { Preguntas abiertas sobre las percepciones personales de las causas que conllevaron al desuso de } \\
\text { las UDIS, así como también de los cambios que hubieran mejorado el sistema. Interpretación de } \\
\text { resultados mediante análisis de contenido (PR, PA) }\end{array}$ \\
\hline
\end{tabular}

FUENTE: Elaboración propia.

Adicionalmente se entrevistaron a personas no participantes de Sinincay buscando identificar si el proyecto fue suficientemente difundido en la comunidad, sobre todo por aquellos que poseían negocios en la parroquia y la razón por la cual no participaron en el mismo. Se utilizaron únicamente dos preguntas simples:

1. ¿Conocía Ud. de un proyecto de dinero alternativo denominado UDIS, impulsado por la Cooperativa de Ahorro y Crédito Integral y la Red de Intercambio Solidario Integral, que se dio más o menos entre los años 2010-2012?

2. Si la respuesta fue afirmativa: ¿Por qué no participó en el proyecto?

El análisis de los datos se realizó tomando como referencia lo estipulado por Corbetta (2007) sobre el análisis de tipo cualitativo, es decir, centrándonos en el sujeto entrevistado y en comprender sus posturas y visiones de los escenarios y condiciones antes mencionados. Para el análisis de datos recurrimos al método de análisis de contenido y como recurso informático trabajamos con Atlas.ti. 


\section{LA IMPORTANCIA DE LA EVALUACION COMO PASO PREVIO A LA IMPLEMENTACION DE UNA MONEDA COMPLEMENTARIA. UN ESTUDIO DE CASO RURAL EN ECUADOR, LA PARROQUIA SININCAY}

\subsection{Evidencia empírica para contrastar el cumplimiento de las condiciones socio- económicas necesarias para el adecuado funcionamiento de las UDIS}

Ante la falta de información se buscó realizar un primer acercamiento al problema descrito comprendiendo el contexto y puntos de vista de los actores sociales que participaron en este SMC. Coincidiendo con Malhotra (2004), es una investigación exploratoria, basada en una muestra que incluye ejecutivos de las instituciones promotoras, algunos participantes y como grupo de control a varios habitantes que no participaron en el proyecto. Todos ellos proporcionaron sus puntos de vista para la comprensión del caso estudiado.

De acuerdo con Hernández et al. (1997), esta investigación cualitativa no se fundamenta en herramientas estadísticas, aunque recurre marginalmente a ella. No se busca generalizar estos resultados y, aunque no debería buscarse su réplica, proponemos justamente que el proceso propuesto pueda constituirse en un método para evaluar las causas de fracasos o éxitos en experiencias similares de SMCs.

\subsubsection{Entrevistas en profundidad}

Se aplicaron dos técnicas de muestreo no probabilístico: muestreo por juicio y muestreo bola de nieve. Se utilizó como herramienta de recolección de datos la entrevista estructurada bajo el principio de saturación. Se diseñaron tres tipos de entrevistas estructuradas: la primera aplicada a 4 funcionarios de las instituciones promotoras (3 ejecutivos y 1 operativo); en segundo lugar, se aplicó una entrevista a 11 participantes (usuarios) del sistema (de una población de 17). En tercer lugar, a un grupo de control conformado por 29 informantes de microemprendimientos que no participaron en el proyecto (de un total de 34 negocios actuales del lugar, siendo 5 de ellos posteriores al proyecto UDIS). Los tipos de preguntas y a quienes se aplicaron se especifican en la segunda columna de la Tabla 2 y que corresponden a las condiciones de la columna primera. Las preguntas fueron realizadas con el propósito de establecer el nivel de cumplimiento de cada una de las condiciones consideradas.

La mayor parte de las entrevistas tuvieron lugar en las viviendas o microemprendimientos de las personas entrevistadas cara a cara, con excepción del representante de la fundación Pachamama que se realizó vía Skype. Las entrevistas fueron individuales en todos los casos. La mayor parte de ellas tuvo una duración entre 40 y 90 minutos.

Los entrevistados fueron seleccionados de acuerdo con un casillero tipológico que buscó controlar la heterogeneidad de la muestra considerando variables analíticamente relevantes. Estas variables estaban relacionadas con diferentes roles que estas personas pudieron jugar en el funcionamiento del sistema UDIS.

Se recabó la percepción de los actores sobre el esquema UDIS y el escenario socioeconómico en el que fue implantado el proyecto, las causas que llevaron al desuso y posterior fracaso de este SMC en la parroquia, y las razones por las que potenciales participantes no fueron parte de esta iniciativa. 
Se utilizaron entrevistas estructuradas, las que, según Romo y Castillo (2002), Corbetta (2007) y Blasco y Otero (2008), recuren a las mismas preguntas para todos los entrevistados, con la misma formulación y en el mismo orden, lo que exige tener un set de preguntas predefinidas. Siendo las preguntas de tipo abiertas, para dejar libertad al entrevistado para que responda como desee. Esto también puede definirse como entrevista estandarizada abierta en términos de Valles (1999), aunque, como advierte este último autor, no siempre fue posible ceñirnos estrictamente al esquema planteado (Valles, 2007).

Las entrevistas estructuradas fueron diseñadas para obtener información enfocada en los escenarios y condiciones concretas identificados previamente. Estos requisitos o condiciones para un adecuado funcionamiento de las UDIS fueron extraídos del análisis de algunos autores que abordan este tema. Cabe indicar, que en nuestra revisión de la literatura encontramos pocos estudios que de manera explícita determinan características adecuadas para el éxito de un SMC. Schuldt (1997) hace un listado de condiciones para garantizar el éxito de estas propuestas, mismas que sirvieron de fundamento para la parte metodológica de esta investigación, complementado por el aporte de otros autores como Hirota (2012), Santana (2011), Riegel (2003), Greco (2003), Cahn y Rowe (1992), Kennedy (1998), Schuldt (1997), Solomon (1996), Steiner (1961), Gesell (1936), Fisher (1933), Keynes (1943), entre otros, aunque ninguno de ellos recurre al análisis de factores de un caso práctico fallido.

\section{Resultados}

\subsection{Sobre los mecanismos de las UDIS}

Los miembros de la red podían comprar libremente UDIS en la Cooperativa Integral, pagando 0,90 USD por cada UDIS de valor nominal 1 USD y no existía un monto límite para la compra de esta moneda. Se esperaba que el descuento del $10 \%$ motive a que existan más asociados y transacciones bajo este sistema. Un promotor explicó: "les motivábamos ofreciéndoles una ganancia (...) el UDIS nosotros vendíamos en 0,90 USD pero sin embargo valía como un dólar, entonces, para los negocios era una ganancia directamente". Un participante testificó que: "un corte de cabello que hago, digamos que cueste 10 dólares, si pagaban con UDIS les terminaba costando 9 dólares, y luego iba a cambiar en la cooperativa, pero me daban por los 10 UDIS los 10 dólares."

Según los entrevistados, no existió un plazo mínimo ni máximo para poder reconvertir las UDIS en dólares por su valor nominal (una relación 1 a 1). Esta falta de control permitía que un asociado pueda comprar UDIS en la cooperativa al $90 \%$ de su precio nominal y al siguiente día reconvertirlas 


\section{LA IMPORTANCIA DE LA EVALUACION COMO PASO PREVIO A LA IMPLEMENTACION DE UNA MONEDA COMPLEMENTARIA. UN ESTUDIO DE CASO RURAL EN ECUADOR, LA PARROQUIA SININCAY}

a dólares al 100\%, sin haber realizado ninguna transacción por productos o servicios de la red. Afortunadamente, ningún testimonio manifestó abusos de este diseño riesgoso.

Este $10 \%$ de subsidio era absorbido por la fundación Pachamama como gasto de promoción de esta moneda y se mantendría hasta que los asociados formen una masa crítica de transacciones y se acostumbren al sistema, lo cual nunca sucedió. El proyecto UDIS se cerró definitivamente en diciembre de 2013. En la actualidad ya no existe la cooperativa Integral y sus exfuncionarios entrevistados no pudieron dar cifras de estas transacciones.

\section{I) Percepciones subjetivas de las condiciones económicas a nivel parroquial en un período de dos años previa aplicación de las UDIS}

\section{i) Crisis económica (incumple)}

La percepción general sobre la existencia de crisis económica a nivel parroquial fue negativa. Se solicitó a los entrevistados que calificaran la situación económica de la parroquia, las calificaciones otorgadas a esta variable fueron: mala $(0 \%)$, regular $(0 \%)$, normal $(53 \%)$, buena $(40 \%)$ y excelente (7\%), estos resultados evidenciarían que este tipo de esquema monetario no podía haberse justificado desde la necesidad de afrontar una situación económica deficiente dentro de la localidad.

\section{ii) Elevado número de negocios quebrados (incumple)}

La percepción de los entrevistados sobre la existencia de un elevado número de negocios quebrados durante el período de referencia y en comparación con otras épocas fue mayoritariamente negativa. El hecho de que 12 de los 15 entrevistados negaran tal situación, indica la existencia de un escenario opuesto al adecuado para aplicar estos SMC.

\section{iii) Caída de la producción y venta de los negocios en Sinincay (incumple)}

El $67 \%$ de los entrevistados consideraron que no existió una caída de la producción y ventas de los negocios en Sinincay antes de la aplicación de las UDIS, tanto a nivel general como de quienes participaron en el proyecto. De hecho, desde el punto de vista de los promotores, la buena producción local (especializada en ladrillos y tejas artesanales) que presumían que existía en la localidad fue considerada como una oportunidad para desarrollar este proyecto monetario alternativo.

\section{iv) Elevados niveles de desempleo (incumple)}

En el caso particular de cada uno de los participantes entrevistados, se determinó que todos tenían sus negocios en pie y funcionando durante la fase previa a la aplicación de las UDIS, incluso algunos mantenían más de un emprendimiento en funcionamiento. 
A nivel parroquial y con base en los datos del VII Censo de Población y VI de Vivienda del 2010, se estimó que la tasa de desempleo en Sinincay fue relativamente baja $(2,07 \%)$, por lo cual no podríamos considerar un escenario económico desfavorable.

\section{v) Escasez de circulante y/o poco poder adquisitivo (incumple)}

Según la información obtenida, 14 de los 15 entrevistados consideran que no hubo una escasez de circulante dentro de la localidad, ni antes ni durante la aplicación de las UDIS. Así también, la totalidad de participantes mencionaron no haber tenido dificultades en cuanto a su capacidad para adquirir bienes y servicios, tanto para el consumo como para el desarrollo de sus actividades productivas. Según testimonios: "falta de dinero no, eso que no todos tienen familias en Estados Unidos [no todos reciben remesas], entonces hay mucha gente en mi parroquia que también se dedicaban al ladrillo, y (...), sí han logrado salir sin dificultad" (participante 11). "Parece que había bastantísimo dinero más bien, porque ponen en cooperativas de acá sus pólizas por 50 y hasta 100 mil dólares" (participante 10).

\section{vi) Contracción del crédito y altas tasas de interés (incumple)}

De acuerdo con los datos, durante el período de referencia, no existió una contracción del crédito reflejada por una reducción de la oferta de operaciones crediticias dadas por entidades financieras locales o en dificultades para acceder a estos servicios financieros. Tampoco se evidenció una percepción de altas tasas de interés; por el contrario, el $53 \%$ de los entrevistados las consideraron como normales y el $40 \%$ como tasas bajas. Así se expresaron los participantes: "bueno, en esa época parece que era más fácil acceder a los créditos, (...), no había mucho papel que presentar" (participante 7); "siempre ha habido buena oferta de créditos, como le digo, si se cumplían con los requisitos -que me parecen que eran mínimos- podíamos acceder a los créditos. Casualmente, en esa época incluso cuando funcionaba los UDIS ofrecían más créditos que lo que hacen ahora." (participante 5)

\section{II) Percepciones subjetivas de las condiciones mínimas establecidas por Schuldt}

\section{i) En lo económico (incumple)}

Se indagó sobre la existencia de proyectos o propuesta de proyectos productivos ya existentes interesados en integrarse al sistema UDIS. También es ideal que surjan nuevos emprendimientos motivados por la presencia del SMC. De acuerdo con la información obtenida, 14 de los 15 entrevistados consideraron que durante el período de referencia sí existieron propuestas de proyectos productivos en la localidad, sin embargo, emergieron como requisito de aprobación de un taller de emprendimiento dictado en la localidad, y que, a decir de los entrevistados, ninguno llegó a la fase de ejecución. 


\section{LA IMPORTANCIA DE LA EVALUACION COMO PASO PREVIO A LA IMPLEMENTACION DE UNA MONEDA COMPLEMENTARIA. UN ESTUDIO DE CASO RURAL EN ECUADOR, LA PARROQUIA SININCAY}

\section{ii) En el campo de especialización productiva (incumple)}

En esta pregunta se identificaron los tipos de actividades productivas y servicios que se desarrollaban en la parroquia. Las categorías señaladas fueron: en artesanías: ladrillos, tejas y artesanías en general. En servicios: restaurantes. En agroalimentaria: crianza de animales y explotación del suelo a través de sembríos. En comercio: tiendas y abacerías.

Esta información muestra mucha limitación en cuanto a diversidad de actividades productivas del lugar, sobre todo en lo que respecta a servicios. De esta limitada diversidad, según las entrevistas (y observación de los microemprendimientos asociados a esta Red de Intercambio Solidario Integral), fueron pocos los tipos de negocios que ingresaron al circuito UDIS lo que limitó las posibilidades de transacciones dentro de la comunidad. Se integraron: 1 panadería, 1 almacén veterinario, 1 papelería, 2 asaderos, 2 ferreterías, 1 peluquería, 1 almacén de artículos para fiestas infantiles, 1 vivero, 1 supermercado barrial, 1 farmacia, 1 joyería artesanal, 1 artesano productor de cocinas industriales, 1 artesano de prendas de vestir tejidas, 1 almacén de muebles y electrodomésticos y 1 restaurante. Cabe indicar que esta zona es conocida por incluir diversos productores de ladrillos artesanales, sin embargo, no consiguieron incluir a ninguno de ellos en el proyecto lo que según algunas entrevistas responde a que su producción se vende básicamente fuera de Sinincay. Esta producción artesanal de ladrillos se ha constituido desde hace muchas décadas en un distrito industrial, en los términos de Becattini (2003) y que quedo al margen de SMC.

Pero el problema no solo era para los consumidores. Una señora dueña de un asadero también se lamentó de la poca practicidad de los UDIS que no eran aceptados por sus diversos proveedores, también de la ciudad.

\section{iii) En lo monetario (cumple parcialmente)}

Todos los actores tuvieron claridad en que las UDIS eran de naturaleza complementaria (no sustitución) y local (circulación solo en Sinincay) frente al dólar americano, la moneda oficial del Ecuador. El objetivo fue robustecer las transacciones entre los habitantes de esta parroquia; sin embargo, su uso fue casi nulo debido al bajo nivel de aceptación del esquema. Las personas y los mismos microemprendimientos preferían mantener sus transacciones en la moneda oficial. Un promotor explicó que:

EI UDIS iba a complementar, igual nunca fue la idea que llegue a sustituirlo [al dólar], (...) más bien lo que nosotros buscábamos es que lleguen a ser complementarios (...) en la medida que haya producción local y que obviamente necesitarán dólares o la moneda oficial para la compra de bienes que no son producidos ahí (promotor 1) 
Según un participante:

Bueno, no podríamos decir que sustituyó, porque lamentablemente no todos creemos en la alternativa solidaria, muchas personas no se convencían de que esa moneda [UDIS] se podía manejar en todo Sinincay, sino más bien éramos solo un grupo que estuvimos conscientes que ese circulaba igual que el dólar normal, era nuestra concepción que se respetaba, si son 10 dólares son 10 UDIS, nos daba igual, pero no toda la gente tenía esa confianza todavía (participante 3)

\section{iv) En lo institucional (cumple parcialmente)}

Se evaluó mediante escala de Likert la capacidad de los promotores para liderar el proceso, introduciendo, divulgando, organizando, controlando y garantizando la continuidad del sistema. De acuerdo con las calificaciones otorgadas por los participantes del esquema, quienes lideraron el proceso sí tuvieron estas capacidades. Sin embargo, las calificaciones otorgadas no fueron unánimes, siendo una condición que se cumplió parcialmente (véase Tabla 3).

\section{Tabla 3. Resultados de calificaciones por variables evaluadas}

\begin{tabular}{|l|ccccc|}
\hline Variables & $\begin{array}{c}\text { Muy en } \\
\text { Capacitad para: }\end{array}$ & $\begin{array}{c}\text { En } \\
\text { desacuerdo }\end{array}$ & $\begin{array}{c}\text { Ni de acuerdo } \\
\text { ni en desacuerdo }\end{array}$ & De acuerdo & Muy de acuerdo \\
\hline Introducir el sistema & $0 / 15$ & $2 / 15$ & $0 / 15$ & $6 / 15$ & $7 / 15$ \\
en la localidad & $(0 \%)$ & $(13.33 \%)$ & $(0 \%)$ & $(40 \%)$ & $(46.67 \%)$ \\
Divulgar el sistema & $0 / 15$ & $1 / 15$ & $4 / 15$ & $3 / 15$ & $7 / 15$ \\
en la localidad & $(0 \%)$ & $(6.67 \%)$ & $(26.66 \%)$ & $(20 \%)$ & $(46.67 \%)$ \\
Organizar el sistema & $0 / 15$ & $0 / 15$ & $2 / 15$ & $5 / 15$ & $8 / 15$ \\
en la localidad & $(0 \%)$ & $(0 \%)$ & $(13.33 \%)$ & $(33.33 \%)$ & $(53.33 \%)$ \\
Controlar el ingreso al & $0 / 15$ & $0 / 15$ & $5 / 15$ & $3 / 15$ & $7 / 15$ \\
sistema en la localidad & $(0 \%)$ & $(0 \%)$ & $(33.33 \%)$ & $(20 \%)$ & $(46.67 \%)$ \\
Garantizar continuidad & $0 / 15$ & $1 / 15$ & $4 / 15$ & $4 / 15$ & $6 / 15$ \\
sistema en la localidad & $(0 \%)$ & $(6.67 \%)$ & $(26.67 \%)$ & $(26.67 \%)$ & $(40 \%)$ \\
\hline
\end{tabular}

FUENTE: Elaboración propia.

\section{v) En lo psicosociológico (incumple)}

En esta condición se indagó principalmente por el nivel de creencia de los actores en el éxito del sistema, los métodos utilizados para motivar a la gente a participar en el proyecto y las razones por las que impulsaron (promotores) y participaron (usuarios) en el sistema UDIS. 


\section{LA IMPORTANCIA DE LA EVALUACION COMO PASO PREVIO A LA IMPLEMENTACION DE UNA MONEDA COMPLEMENTARIA. UN ESTUDIO DE CASO RURAL EN ECUADOR, LA PARROQUIA SININCAY}

De acuerdo con los datos obtenidos, el $53 \%$ de los entrevistados creían en el éxito del esquema y el $47 \%$ restante no. Entre las razones que determinaron el elevado porcentaje de desinterés en el sistema están: a) muy alta confianza en la moneda de curso legal, el dólar americano; b) inexistencia de una visión de comunidad y c) el juzgar innecesaria una moneda alternativa en la localidad. De acuerdo a un promotor entrevistado:

la mayor parte de personas están acostumbradas ya a una unidad monetaria, por lo tanto, era complicado realmente promover otra, más que nada considerando de que no todos tuvieron el conocimiento y hay personas que no confían en sí en algo nuevo que se les va a ofertar, entonces por eso no era tan seguro que funcione (promotor 3 )

Según un participante:

Fui uno de los que me presenté con aspecto negativo desde el inicio, porque, si nosotros, digamos, en nuestra vida normal tenemos el dólar, y que vengan con otra moneda era bien difícil (...), y no sé el motivo de por qué, si tenemos el dólar con el que tranquilamente manejamos, para qué tener otra moneda, o sea, cuál era el objetivo. Incluso eso fue motivo de investigaciones a nivel nacional, porque aquí llegó un periódico importantísimo -creo que fue de Guayaquil 0 de Quito- que hicieron una investigación al respecto y para ver el por qué, quiénes autorizaron, si está normado por la ley o la Superintendencia de Bancos, etc. (participante 6)

El mecanismo utilizado para promocionar las UDIS fue principalmente el subsidio (10\%) explicado previamente. En segundo lugar, estuvo la motivación de tipo social, mediante la oferta de capacitaciones y talleres a quienes participaban en el proyecto.

De las entrevistas a los promotores se puede interpretar que estos tuvieron principalmente motivaciones políticas de las instituciones involucradas buscando su mejor posicionamiento dentro de esta comunidad. Es de suponer que estas motivaciones políticas fueron justificativos suficientes para ejecutar el proyecto por parte de estas instituciones y no haberse cuestionado sobre el cumplimiento las condiciones propicias. Según un promotor:

Al poder hacer estos medios de pago, pues iba a fomentarse la mayor difusión de la cooperativa, iba a beneficiar a la cooperativa en cuanto a liquidez. (...). Promovimos este medio novedoso de intercambio para hacer de la cooperativa con alguna cosa que le diferencie de lo que hacían las demás (promotor 2)

Según otro promotor:

En general como Fundación Pachamama trabajamos por un modelo de desarrollo sostenible basado en el Buen Vivir y el respeto a la naturaleza para todo el Ecuador. Lo que pretendíamos es que nuestra propuesta de SMCs promuevan también una economía sostenible 
para el país. Entonces por el tipo de contrapartes que encontramos, no trabajamos directamente en la Amazonía, que era donde se enfocaba básicamente nuestro trabajo, sino más bien lo que encontramos fue que podíamos también hacer proyectos piloto en estas localidades de la sierra que potencialmente presentaban un mayor impacto para mostrar resultados, para posteriormente buscar alternativas de cómo hacer estos proyectos locales dentro de comunidades amazónicas. Entonces esa era nuestra motivación principal. (promotor 1)

Por otra parte, en el caso de los participantes, más que la función de intercambio de esta moneda para motivar la producción y el comercio entre ellos, principalmente fueron motivados por el mecanismo de subsidios que estas incluían y que se efectivizaban cuando las UDIS finalmente se canjeaban nuevamente por dólares.

\section{vi) En lo educativo (cumple)}

Schuldt (1997) menciona que el nivel de educación formal más bajo compatible con cualquiera de las formas que tome un SMC es prácticamente la inexistencia de analfabetos entre sus participantes. Según los resultados al iniciar el proyecto de las UDIS el 27\% de los participantes había culminado educación general básica superior (décimo año de educación básica), 37\% bachillerato, 27\% educación superior universitaria y el $9 \%$ postgrado universitario, no existiendo participantes analfabetos incluidos en el proyecto.

\section{vii) En lo cultural (incumple)}

Según Schuldt (1997), convendría que la comunidad que adopte un SMC cuente con un conjunto de normas, expectativas y valores relativamente comunes. Lo cultural influye en el tipo de bienes que se consume y una concordancia facilita un proyecto compartido. Por ejemplo, las fiestas religiosas provocan rituales de intercambio de regalos y fiestas familiares que promueven el consumo de cierto tipo de bienes y servicios comunes.

Esta condición evitaría una excesiva diversificación de productos y servicios requeridos en una comunidad. Sin embargo, la diversificación requerida por los habitantes es superior a lo esperada. Sobre este aspecto algunos entrevistados comentaron que preferían comprar en la ciudad (Cuenca) justamente porque en Sinincay "no cuentan con mucha variedad de productos necesarios ni tampoco precios convenientes", recordando que en la ciudad no se puede pagar con UDIS.

\section{viii) En lo político (incumple)}

Para el cumplimiento de esta condición se analizaron las percepciones de los actores del proyecto respecto a la moneda oficial, así como sobre la situación económica y social del país en el período previo a las UDIS. 


\section{LA IMPORTANCIA DE LA EVALUACION COMO PASO PREVIO A LA IMPLEMENTACION DE UNA MONEDA COMPLEMENTARIA. UN ESTUDIO DE CASO RURAL EN ECUADOR, LA PARROQUIA SININCAY}

Con respecto al dólar la percepción fue positiva (80\%), afirmando que, a pesar de no ser la moneda propia del país, esta divisa ha brindado ventajas y beneficios por tratarse de una moneda fuerte, competitiva y de alta aceptación. La percepción sobre la situación económica y social del país en el período de referencia también fue positiva (100\%), incluso enfatizan en que, durante esos años, por parte del gobierno hubo mucha inversión en el ámbito social, por haber sido un gobierno altamente apegado a los intereses populares. Un promotor sostuvo que: "Creo que [el dólar] nos ha beneficiado en algunos aspectos, al tratarse en sí de una moneda fuerte y bienvenida por cualquiera, antes incluso teniendo el sucre [moneda de Ecuador antes del 2000] si alguien nos ofrecía pagar en dólares lo aceptábamos" (promotor 2). Según un participante:

Bueno, sabemos que [el dólar] no es nuestra moneda propia, pero es la que se maneja en todo el país y tenemos que acoplarnos, diría que nos ha traído más ventajas que desventajas a nuestra economía, porque de lo que he visto y de lo que he hablado, por ejemplo, con mis papás, como que todo está más estable ahora (participante 8)

Según otro participante: "[el dólar] es la que a uno nos identifica ahora, en cambio con el UDIS, una moneda a lo mejor solamente momentánea" (participante 4). Según otro promotor:

La situación económica y social en esos años fue buena, hay que reconocer que durante ese gobierno [Presidencia de Correa] se invirtió mucho en el ámbito social que venía de una buena situación económica del país porque en esas épocas el precio del petróleo que es la principal fuente de ingresos para el Ecuador estaba en los más altos precios históricos (promotor 1)

\section{III) Dinámica del funcionamiento del sistema monetario heterodoxo}

\section{i) Estudio previo (cumple parcialmente)}

Los resultados muestran que los promotores del esquema UDIS sí realizaron un estudio de factibilidad previo, sin embargo, se limitó a un diagnóstico breve de parroquia. En dicho estudio se pone énfasis en la descripción de las condiciones económicas de la entidad financiera que se encargó de la emisión de las UDIS dentro de la localidad. Un promotor explicó que: "Sí, hicimos un estudio de factibilidad, para aplicar en la parroquia, para con sus resultados ver si es posible aplicar en comunidades de la Amazonía" (promotor 1). Según otro promotor: "al inicio se desarrolló un estudio de factibilidad, pero (...) se hizo un diagnóstico breve, pero creo que faltó mayor detenimiento y profundidad en el estudio" (promotor 2) 


\section{ii) Validez circunscrita en el tiempo y espacio geográfico (cumple parcialmente)}

La información obtenida señala que las UDIS no tenían un tiempo definido de uso o una fecha de caducidad especificada en cada billete, característica que, evitaría justamente el que los tenedores de UDIS canjeen tempranamente por su equivalencia en dólares, manteniendo un mayor tiempo de circulación en el mercado local. Según el testimonio de un promotor: "parece que era una de las cosas que no tenía el billete. Si no estoy mal, parece que no tenía, y esa era una de las observaciones que nos hicieron los holandeses cuando pasó todo esto de reconocer a los billetes." (promotor 4).

En cuanto a la validez de las UDIS en el espacio geográfico, ésta fue una condición que sí se cumplió puesto que no podía ser utilizado fuera del circuito cerrado de comercio, es decir dentro de la red de Sinincay.

\section{iii) Oxidación o depreciación programada (incumple)}

La oxidación o depreciación programada es una característica que identifica a diversos SMCs. Su objetivo es evitar el atesoramiento y garantizar la circulación de la moneda en períodos específicos de tiempo. En el caso de las UDIS éstas no estaban sujetas a oxidación o depreciación programada. La decisión de no aplicar este mecanismo fue de la entidad financiera promotora la Cooperativa Integral. Un promotor explicó que:

No estaban obligadas a circular las UDIS cada cierto tiempo, o sea, analizamos siempre esa posibilidad, pero como te decía, eso pasaba siempre por decisiones de la cooperativa. Nosotros [Fundación Pachamama] hicimos sugerencias al respecto, pero ellos decidieron que no. Nosotros analizamos una gran variedad de sistemas y el tema de la oxidación era muy recurrente por eso lo sugerimos. (promotor 1)

\section{iv) Emisión y canje (cumple parcialmente)}

Como explicamos previamente, el proceso de emisión de las UDIS fue realizado mediante una venta por dinero oficial en la cual se aplicó un descuento del 10\% que le permitía incrementar el poder adquisitivo del comprador. Por otra parte, el canje de UDIS por dinero oficial podía ser efectuado en cualquier momento sin aplicar ninguna penalización equivalente a una cuota de oxidación o de vencimiento, por el contrario, el cambio reconocía un dólar por un UDIS, es decir conservaba los 10 centavos de beneficio de la compra sin restricciones. En teoría se podía comprar UDIS a 0,90 USD y en poco tiempo venderlas en 1,00 USD a la misma institución financiera sin haber realizado transacciones en la comunidad. Un promotor sostenía que: "[cualquier persona] tenía que comprar las UDIS, cuando usted compraba lo hacía a 90 ctvs, ahí le daba a usted mayor poder de adquisición porque dentro de la red el UDIS valía lo mismo que un dólar." (promotor 4). Otro promotor comentaba que "Io podía canjear cualquier persona, no solamente participantes, al momento del cambio había un beneficio." (promotor 1) 


\section{LA IMPORTANCIA DE LA EVALUACION COMO PASO PREVIO A LA IMPLEMENTACION DE UNA MONEDA COMPLEMENTARIA. UN ESTUDIO DE CASO RURAL EN ECUADOR, LA PARROQUIA SININCAY}

\section{v) Tiempo de funcionamiento (incumple)}

Según los datos obtenidos, no existió un tiempo definido para la aplicación de estas monedas dentro de la parroquia. Las opiniones de los entrevistados fueron totalmente diversas: un promotor consideró que el proyecto tenía una duración de 2 años, otro menciona que fue para 3 años, otro indica que era un proyecto de mediano y largo plazo e incluso hay una opinión de que no hubo ningún tiempo específico. Adicionalmente, se hizo una revisión del estudio de factibilidad del proyecto el cual tampoco especifica el tiempo de duración del esquema.

\section{IV) Percepción de las causas que conllevaron a la terminación del proyecto}

Con base en la información recabada, se han categorizado las causas por factores internos y factores externos que afectaron el correcto funcionamiento del esquema UDIS.

Entre de los factores internos que los actores consideraron están: la escasa circulación de las UDIS; la poca aceptación de las mismas; poca diversidad productiva; poca información y capacitación sobre el tema; la necesidad de ganar de forma individual. Según un promotor: "la gente no le daba la fluidez que queríamos, apenas tenían UDIS se iban a la cooperativa a cambar por dólares" (promotor 4). Según un participante: "yo creo que fue la falta de confianza de nuestros hermanos de la parroquia, no me imagino qué más podría haber hecho que se acaben las UDIS aqui" (participante 11). EI testimonio de otro participante: "primeramente, el desinterés y desconfianza de la gente, de no saber de dónde salió esa moneda, de no saber para qué llegó aquí, quién o quiénes fueron los que promocionaron esto, entonces pasó por desapercibido." (participante 6)

Como factores externos fueron considerados: el boom mediático que en su momento tergiversó la concepción y finalidad del proyecto, planteando incluso que era ilegal y que se pretendía desplazar al dólar como moneda oficial; y, la prohibición legal (a través de la Ley Orgánica de Economía Popular y Solidaria) que impidió que las entidades financieras populares y solidarias manejen todo tipo de medios de pago alternativos. Uno de los promotores sostuvo que:

Los medios de comunicación se encargaron de hacer tener miedo, un poco de temor en la gente, en el cómo se imprimió, que no era legal, que por si acaso se va a dar una estafa, que era un inicio de cambio de moneda, que estábamos por perder el dólar (promotor 2) 


\section{Discusión}

Un sistema monetario complementario (SMC) es necesario cuando el sistema oficial no cumple adecuadamente con sus objetivos dentro de una determinada comunidad. Por otra parte, coincidiendo con Meyer y Hudon (2018), estos SMCs pueden tomar diferentes formas según sean las características socioeconómicas de las comunidades, sus valores y procesos organizativos involucrados en la producción y distribución. Así por ejemplo, Bendell (2017) sostiene que las pymes necesitan un tipo diferente de moneda complementaria y que no necesariamente implican monedas bajo sofisticados sistemas informáticos como el Bitcoin.

En el presente estudio hemos recogido 19 características sugeridas principalmente por Schuldt (1997) y, mediante los testimonios de algunos promotores y participantes del fallido sistema de UDIS de Sinincay, hemos analizado si hubo el cumplimiento de cada una de ellas. De manera general, tanto promotores, participantes como no participantes entrevistados consistentemente evidenciaron un escenario no propicio para el funcionamiento de las UDIS. Según los testimonios, apenas una de las condiciones evaluadas se cumplía, mientras que trece no se cubrían y cinco lo hacían parcialmente. Además, justamente la única característica cumplida, el nivel de educación, no implica un propósito de un SMC, es decir una deficiencia a superar, sino más bien una característica de la población que permitiría un mejor entendimiento del funcionamiento de este mecanismo.

De acuerdo con las entrevistas realizadas a los mismos promotores, este proyecto no tuvo como principal motivación la dotación de un recurso que permita paliar problemas concretos de la población de Sinincay. De hecho, no partieron de un diagnóstico de dichos problemas, lo que niega la posibilidad de un adecuado diseño de este proyecto.

Así también, en los testimonios de los mismos habitantes no se reconoce la existencia de alguna crisis económica local, crisis que para ciertos autores puede ser un justificativo para su aplicación. Con respecto a otros condicionantes, los entrevistados sostienen que la situación económica dentro de la parroquia fue buena, que no hubo escasez de circulante, ni tasas de interés altas que incidan en una contracción del crédito (contracción de la masa monetaria). Tampoco se contó con elevados índices de desempleo, ni hubo una caída en la producción y ventas, ni quiebras y cierres significativos de negocios.

En lo que respecta a las condiciones mínimas estipuladas por Schuldt (1997), en su mayoría no se cumplen. Este autor menciona que una localidad que desee aplicar un SMC debe tener actividades con amplia diversificación, lo que no corresponde al caso de estudio, aunque es verdad que la institución patrocinadora en su momento incentivó la generación de nuevos proyectos productivos pero que lamentablemente no se concretaron. Esta limitada diversidad de actividades obliga a que la mayo- 


\section{LA IMPORTANCIA DE LA EVALUACION COMO PASO PREVIO A LA IMPLEMENTACION DE UNA MONEDA COMPLEMENTARIA. UN ESTUDIO DE CASO RURAL EN ECUADOR, LA PARROQUIA SININCAY}

ría de los bienes y servicios requeridos no puedan ser negociados con UDIS, optándose por comprar fuera de la localidad mediante dólares, la moneda oficial.

Los mecanismos de motivación por parte de los promotores no fueron los adecuados. En lugar de robustecer un desarrollo colectivo, estimularon el interés individual a través de una subvención económica que se concretaba irrestrictamente en el canje de UDIS por dólares en la misma institución financiera patrocinadora del proyecto.

Las motivaciones de los mismos promotores para llevar a cabo el proyecto no coincidían con los objetivos del esquema, no estuvieron enfocadas en el beneficio socioeconómico de la población, sino en el mejoramiento del posicionamiento institucional en esta localidad.

Por otra parte, se constató poca confianza y credibilidad de los participantes en el esquema monetario adoptado. Esta condición pudo determinarse por la excesiva preferencia de la población por el dólar. Esta situación no mejoró ante la falta de capacitación y difusión del uso del sistema UDIS creando especulaciones negativas sobre su utilidad.

En relación con la dinámica de funcionamiento del SMC, en su mayoría tampoco se cumplió. El estudio de factibilidad del proyecto no evaluó previamente si el escenario socioeconómico de Sinincay era el adecuado. Careció de un análisis de las limitaciones económicas y culturales existentes, de las posibilidades y recursos disponibles, de las bases sociales de apoyo, etc. De hecho no puede justificarse un proyecto de esta naturaleza con objetivos generales como "colaborar con el desarrollo de la comunidad" sino debe contar con propósitos concretos que impliquen cubrir deficiencias plenamente identificadas del sistema monetario oficial y que sirvan de base para su diseño.

El sistema de las UDIS tampoco incluyó mecanismos recomendados de oxidación o depreciación programada, características que, según algunos autores, propenden a evitar el atesoramiento de esta moneda y estimular su circulación para dinamizar una producción y comercio que se presumen estacados. Es verdad que no todos los SMCs exitosos cumplen estas características, sin embargo, en el caso de Sinincay, la ausencia de un mecanismo de oxidación, así como la falta de caducidad de los billetes, tampoco lograron dinamizar el mercado local mediante esta moneda complementaria.

El proceso de emisión y canje de las UDIS no incluía un mecanismo de monitoreo de transacciones realizadas mediante este dinero. Por lo contrario, el subsidio de 10 ctvs por dólar que se efectivizaba al canjear UDIS por dólares, representaba un incentivo para su pronta conversión incondicional. Este subsidio equivalía a una rentabilidad del 10\%, posiblemente superior a la generada por los microemprendimientos participantes. En este sentido, no había una conexión adecuada entre dicho subsidio y un proceso de incentivo a la producción y mercado comunal.

Bajo el criterio de que estos sistemas pueden servir para cubrir diferentes necesidades en diferentes comunidades, no necesariamente se deben cubrir los mismos requisitos en todos los casos. 
Así, es probable que las UDIS puedan ayudar mejor en la dinamización de un mercado en comunidades con limitaciones económicas, conviniendo entonces el mecanismo de oxidación. Sin embargo, este mecanismo puede ser innecesario, e incluso inconveniente, en SMCs como el Bitcoin orientados a la especulación o la libra de Brixton (UK) cuyo propósito principal no es dinamizar el mercado sino evitar que el dinero de esta región salga rápidamente al exterior: "La libra de Brixton $(B £)$ es dinero que se adhiere a Brixton" (Brixton Pound, s.f.). Por lo tanto, en el futuro, convendría realizar investigaciones que permita profundizar en esta categorización.

Por otra parte, gracias a los avances informáticos, un SMC podría fortalecerse significativamente si se combina con un concepto emergente como la economía colaborativa, pero, como sostienen Falcon y Fuentes (2019), esto requiere sustituir su enfoque competitivo por el cooperativo.

\section{Conclusión}

La naturaleza cualitativa de esta investigación no permite ponderar la importancia de cada una de las características socioeconómicas identificadas como posibles requisitos para un adecuado funcionamiento de las UDIS, sin embargo, se consigue un primer acercamiento para identificar las causas del fracaso de este SMC en la parroquia Sinincay. Sin duda, un estudio posterior podría ayudar establecer estas ponderaciones desde una perspectiva cuantitativa.

Por otra parte, los autores como Schuldt (1997) que nos sirvieron para identificar requisitos de éxito de los SMC, no especifican si todos ellos son indispensables, pero cabe suponer que no necesariamente es así, ya que existen casos exitosos con o sin oxidación en el diseño, con y sin presencia de crisis en las características socioeconómicas. Sin embargo, es de esperarse que un SMC se justifique siempre que se constituya en un recurso para cubrir algún tipo de deficiencia del sistema monetario oficial y que la comunidad involucrada confíe en el recurso.

Basados en las evidencias, nuestra conclusión es que las UDIS no tuvieron un adecuado análisis previo que permita identificar las condiciones socioeconómicas en la cuales jugaría un papel importante y, sobre todo, de haberlo realizado se hubiera determinado que las condiciones previas al proyecto no eran propicias para implantar un SMC. Según los testimonios, Sinincay estaba demasiado integrada a la dinámica económica de la ciudad de Cuenca, más que entre los mismos pobladores de la parroquia. Por otra parte, los dólares que circulaban entre sus moradores, incrementados por las significativas remesas de sus migrantes, no evidencian debilidades en la moneda oficial, reforzada por una disposición de créditos considerados como asequibles. 


\section{LA IMPORTANCIA DE LA EVALUACION COMO PASO PREVIO A LA IMPLEMENTACION DE UNA MONEDA COMPLEMENTARIA. UN ESTUDIO DE CASO RURAL EN ECUADOR, LA PARROQUIA SININCAY}

Una consecuencia importante de estos resultados es que, para el caso de nuevos proyectos, el Estado debería exigir un estudio previo por parte de los promotores verificando si el sistema monetario oficial es ineficiente en relación con el propósito que se le quiera asignar al SMC, caso contrario, sería una herramienta innecesaria y por tanto un desperdicio de recursos de los promotores y de la comunidad involucrada. Pero no solo una evaluación del escenario previo, sino también debe exigirse un monitoreo de dichas condiciones socioeconómicas durante la ejecución de cada proyecto, ya que estas pueden cambiar y por ende, un SMC podría dejar de ser útil luego de años de funcionamiento como pudo ser el caso de las UDIS en la Red Comal de Honduras.

\section{Referencias}

BANCO MUNDIAL (2018): El Banco Mundial Trabajamos por un mundo sin pobreza. Recuperado el 6 de Julio de 2018, de Banco Mundial Web site:

http://documents.worldbank.org/curated/en/835601530818848154/pdf/Ecuador-SCD-final-june25-06292018.pdf

BECATTINI, G., BELLANDI, M. \& DEI OTTATI, G. (2003): From Industrial Districts to Local Development, Cheltenham: Edward Elgar.

BENDELL, J. (2017): "Currency Innovation for Sustainable Financing of SMEs: Context, Case Study and Scalability", The Journal of Corporate Citizenship; Sheffield, 67, 39-62.

BLANC, J. (2002): "Formes et rationalités du localisme monétaire", L'Actualité économique, Sept, 247369.

BLASCO, T. \& OTERO, L. (2008): "Técnicas conversacionales para la recogida de datos en investigación cualitativa: La entrevista (I)", Nure Investigación.

BRENES, E. (2013): "Monedas complementarias y ambiente", Cuides (Cuaderno Interdisciplinar de Desarrollo Sostenible), 10, 111-147.

BRIXTON POUND. (s.f.): What is the Brixton Pound?, Recuperado el 24 de 05 de 2019, de Brixton Pound: http://brixtonpound.org/what.

CAHN, E. \& ROWE, J. (1992): Time Dollars: The New Currency That Enables Americans to Turn Their Hidden Resource -Time- into Personal Security and Community Renewal, Emmaus, Pensilvania, Estados Unidos: Rodale Press.

CORBETTA, P. (2007): Metodología y técnicas de investigación social. Madrid, España: McGraw-Hill.

CORRONS, A. (2015): Monedas complementarias en pro de la sostenibilidad y el desarrollo: enfoque panárquico (Tesis), Valencia, España: Universitat Jaume I - Universitat de València. 
CORTÉS, F. (2008): Las monedas sociales, España: CAJAMAR.

DEMEULENAERE, S. (2007): "2006 Annual Report of the Worldwide Database of Complementary Currency Systems". International Journal of Community Currency Research, 11, 23-35. DOI: http://dx.doi.org/10.15133/j.ijccr.2007.003.

DORIA, L. \& FANTACCI, L. (2018): "Evaluating complementary currencies: from the assessment of multiple social qualities to the discovery of a unique monetary sociality", Quality and Quantity; Dordrecht, 52(3), 1291-1314.

DOUTHWAITE, R. (2000): The Ecology of Money (Schumacher Briefing, 4), Totnes, Reino Unido: Green Books.

EL COMERCIO (11 de mayo de 2011): "Las UDIS circulan desde ayer en otra parroquia cuencana. CUenca, Azuay, Ecuador". Obtenido de https://www.elcomercio.com/actualidad/negocios/udis-circulan-ayer-parroquia-cuencana.html.

EL UNIVERSO (4 de mayo de 2011): "Moneda social UDIS genera debate sobre su legalidad y otra propuesta". Obtenido de https://www.eluniverso.com/2011/05/04/1/1356/moneda-social-udisgenera-debate-sobre-legalidad-otra-propuesta.html.

FALCÓN-PÉREZ, C.E. \& FUENTES-PERDOMO, J. (2019): "Mejorando el bienestar de la sociedad a través del cooperativismo de plataforma", CIRIEC-España, Revista de Economía Pública, Social y Cooperativa, 95, 161-190, DOI: 10.7203/CIRIECE.95.12655.

FARE, M. \& OULD AHMED, P. (2017). "Complementary Currency Systems and their Ability to Support Economic and Social Changes", Development and Change, 48(5), 847-872. DOI: https://doi.org/10.1111/dech.12322

FISHER, I. (1933): STAMP SCRIP, New York, Estados Unidos: Adelphi Company.

GARRISON, R. (1996): "Central Banking, Free Banking, and Financial Crises", Review of Austrian Economics, 9(2), 109-127.

GESELL, S. (1936): El orden económico natural por libretierra y libremoneda. Tomo I, Buenos Aires, Argentina: E.F. Gesell.

GRECO, T.H. (2003): Money and Debt: A Solution to the Global Crisis (2nd Ed. PDF ed.), Tucson, Estados Unidos: Thomas H. Greco, Jr.

HERNÁDEZ, R., FERNÁDEZ, C. \& BAPTISTA, P. (1997): Metodología de la Investigación, México D.F., México: McGraw-Hill.

HIROTA, Y. (2012): Monedas sociales y complementarias (MSCs): Experiencias, su papel en la economía social, estrategias, marketing y políticas públicas (Trabajo de Fin de Máster), Valencia, España: Universitat de València. 


\section{LA IMPORTANCIA DE LA EVALUACION COMO PASO PREVIO A LA IMPLEMENTACION DE UNA MONEDA COMPLEMENTARIA. UN ESTUDIO DE CASO RURAL EN ECUADOR, LA PARROQUIA SININCAY}

HIROTA, Y. (2017): Monedas sociales y complementarias (MSCs). Sus valores socioeconómicos para distintos stakeholders (Tesis), Valencia, España: Universitat de València.

IMS (2015): EI WIR, la moneda complementaria Suiza en activo desde 1934. Obtenido de IMS: http://www.monedasocial.org/wir-suiza-1934/, 18 de octubre de 2018.

INEC (2018): Banco de Información, Obtenido de INEC: http://www.ecuadorencifras.gob.ec/banco-deinformacion/.

KENNEDY, M. (1998): Dinero sin inflación ni tasas de interés: Cómo crear un medio de intercambio que sirva a todo el mundo y proteja la Tierra, Buenos Aires, Argentina: del Nuevo Extremo.

KEYNES, J.M. (1943): Teoría general de la ocupación, el interés y el dinero, México D.F., México: Fondo de Cultura Económica.

LIETAER, B. (2005): El futuro del dinero, Buenos Aires: Longseller.

LIETAER, B. \& BELGIN, S. (2011): New Money for a New World. Boulder, Colorado, Estados Unidos: Qiterra Press.

LOUGE, C. (2017): Keynes \& Gesell ¿Nuevo Paradigma?, Buenos Aires: ERREPAR.

MALHOTRA, N.K. (2004): Investigación de Mercados: Un Enfoque Aplicado, México D.F., México: Pearson Education.

MEYER, C. \& HUDON, M. (2018): "Money and the Commons: An Investigation of Complementary Currencies and Their Ethical Implications", Journal of Business Ethics, 1-16. DOI: https://doi.org/10.1007/s10551-018-3923-1.

ORZI, R. (2012): "La moneda social como institución necesaria en la transición hacia 'otra economía". En: Moneda social y mercados solidarios II: La moneda social como lazo social, 95-175.

POLANYI, K. (2001): The Great Transformation: the Political and Economic Origins of Our Time, 2nd Ed. ed. Boston: Beacon Press.

RIEGEL, E. (2003): Flight from Inflation, Los Angeles: The Heather Foundation.

ROMO, M. \& CASTILLO, C. (2002): "Metodologías de las Ciencias Sociales aplicadas al estudio de la nutrición", Revista chilena de nutrición, 29(1), 14-22.

ROTHBARD, M.N. (1979): Moneda, libre y controlada, Buenos Aires: Fundación Bolsa de Comercio de Buenos Aires.

SÁNCHEZ, P. (2019): "La red Comal y las unidades de intercambio solidario (UDIS): una historia de apropiación y resiliencia navegando entre contradicciones", International Journal of Community Currency Research, 23, 83-92, DOl:http://dx.doi.org/10.15133/j.ijccr.2019.008.

SANTANA, M. (2011): "Recrear el dinero en una economía solidaria", Polis, 10(29), 261-280. 
SCALFONI, A. \& CARVALHO DE FRANÇA FILHO, G. (2017): "O paradoxo das Palmas: análise do (des)uso da moeda social no 'bairro da economia solidária"', Cadernos EBAPE.BR, 15(1), 169193.

SCHULDT, J. (1997): Dineros Alternativos para el Desarrollo Local, Lima, Perú: Centro de Investigación de la Universidad del Pacífico.

SEYFANG, G. \& LONGHURST, N. (2013): "Growing green money? Mapping community currencies for sustainable development", Ecological Economics, 86, 65-77. DOI: https://doi.org/10.1016/j.ecolecon.2012.11.003.

SOLOMON, L. (1996): Rethinking Our Centralized Monetary System. The Case for a System of Local Currencies, Westport, CT: Praeger.

STEINER, R. (1961): Die Kernpunkte der sozialen frage, Dornach, Suiza: Rudolf Steiner Verlag.

VALLES, M. (1999): Técnicas cualitativas de investigación social, Madrid: Síntesis.

VALLES, M. (2007): Entrevistas cualitativas, Madrid: CIS.

WILD, L. (2011): El dinero o la vida. Una guía práctica para la alquimia monetaria, Quito, Ecuador: Mayor Books.

ZAGATA, L. (2004): "Complementary currency systems as a source of endogenous development of Iocalities". Agric. Econ. - Czech, 50, 477-484. DOI:10.17221/5236-AGRICECON.

ZELMANOVITZ, L. (2011): "Money: origin and essence", Criterio Libre, 9(14), 65-90. 